\title{
Erratum zu: Einfluss von Merkmalen ebener Figuren auf das Erkennen von Achsensymmetrie - Eine Analyse von Aufgabenlösungen
}

\author{
Daniela Götz • Hedwig Gasteiger • Maria Kühnhenrich
}

Online publiziert: 21. Juli 2021

(C) Der/die Autor(en) 2021

\section{Erratum zu:}

\section{J Math Didakt 2020}

https://doi.org/10.1007/s13138-020-00163-2

Der Artikel „Einfluss von Merkmalen ebener Figuren auf das Erkennen von Achsensymmetrie - Eine Analyse von Aufgabenlösungen“ von Daniela Götz, Hedwig Gasteiger und Maria Kühnhenrich wurde ursprünglich Online First ohne „Open Access“ auf der Internetplattform des Verlags publiziert. Nach der Veröffentlichung in Bd. 41, Heft 2, pp. 523-554 hatten sich die Autoren für eine „Open Access“Veröffentlichung entschieden. Das Urheberrecht des Artikels wurde deshalb in (C) Der/die Autor(en) 2021 geändert.

Funding Open Access funding enabled and organized by Projekt DEAL. Open Access

Open Access Dieser Artikel wird unter der Creative Commons Namensnennung 4.0 International Lizenz veröffentlicht, welche die Nutzung, Vervielfältigung, Bearbeitung, Verbreitung und Wiedergabe in jeglichem Medium und Format erlaubt, sofern Sie den/die ursprünglichen Autor(en) und die Quelle ordnungsgemäß nennen, einen Link zur Creative Commons Lizenz beifügen und angeben, ob Änderungen vorgenommen wurden.

Die Online-Version des Originalartikels ist unter https://doi.org/10.1007/s13138-020-00163-2 zu finden.

Daniela Götz $(\bowtie) \cdot$ Hedwig Gasteiger · Maria Kühnhenrich

Universität Osnabrück, Albrechtstraße 28A, 49076 Osnabrück, Deutschland

E-Mail: daniela.goetz@uni-osnabrueck.de

Hedwig Gasteiger

E-Mail: hedwig.gasteiger@uni-osnabrueck.de

Maria Kühnhenrich

E-Mail: mkuehnhenric@uni-osnabrueck.de 
Die in diesem Artikel enthaltenen Bilder und sonstiges Drittmaterial unterliegen ebenfalls der genannten Creative Commons Lizenz, sofern sich aus der Abbildungslegende nichts anderes ergibt. Sofern das betreffende Material nicht unter der genannten Creative Commons Lizenz steht und die betreffende Handlung nicht nach gesetzlichen Vorschriften erlaubt ist, ist für die oben aufgeführten Weiterverwendungen des Materials die Einwilligung des jeweiligen Rechteinhabers einzuholen.

Weitere Details zur Lizenz entnehmen Sie bitte der Lizenzinformation auf http://creativecommons.org/ licenses/by/4.0/deed.de. 